\title{
The ARMR Classification System and the Modified Hoek-Brown Failure Criterion Compared to Directional Shear Strength Models for Anisotropic Rock Masses
}

\author{
Charalampos Saroglou', Neil Bar²* \\ ${ }^{1}$ School of Civil Engineering, National Technical University of Athens, Zografou, 15773 Athens, Greece \\ 2 Gecko Geotechnics Pty Ltd, P. O. Box 14226, QLD 4868, Cairns, Australia \\ * Corresponding author, e-mail: neil@geckogeotech.com
}

Received: 31 July 2019, Accepted: 10 October 2019, Published online: 11 December 2019

\begin{abstract}
The anisotropic rock mass rating classification system, ARMR, has been developed in conjunction with the Modified Hoek-Brown failure to deal with varying shear strength with respect to the orientation and degree of anisotropy within an anisotropic rock mass. Conventionally, ubiquitous-joint or directional shear strength models have assumed a general rock mass strength, typically estimated using the Hoek-Brown failure criterion, and applied a directional weakness in a given orientation depending on the anisotropic nature of the rock mass. Shear strength of the directional weakness is typically estimated using the Barton-Bandis failure criterion, or on occasion, the Mohr-Coulomb failure criteria. Directional shear strength models such as these often formed the basis of continuum models for slopes and underground excavations in anisotropic rock masses. This paper compares ARMR and the Modified HoekBrown failure criterion to the conventional directional shear strength models using a case study from Western Australia.
\end{abstract}

Keywords

rock mass classification, slope stability, anisotropy, heterogeneous ground conditions

\section{Introduction}

Directional shear strength models allow the application of different shear strengths to different slip surface orientations in numerical analyses. They can be applied in such a way so as to ubiquitously represent weaker bedding planes and foliations upon which shearing is expected to preferentially occur relative to the remainder of the rock mass. In order to apply such models, it is necessary to determine the shear strength of intact rock or rock mass shear strength, the shear strength of the anisotropy plane and define the 'transition' from intact rock or rock mass shear strength to anisotropy plane shear strength $[1,2]$.

Linear approximations of non-linear shear strength envelopes derived from Hoek et al. [3] or Barton and Bandis $[4,5]$ failure criteria can be used to predict the behavior of rock masses and bedding in numerical analyses.

An alternative approach is to determine the strength of anisotropic rock masses for different orientations of the anisotropy plane by using the anisotropic rock mass rating system, ARMR [6], in conjunction with the Modified Hoek-Brown failure criterion [7]. Using this method, both the shear strength of the intact rock and rock mass strength (in terms of Hoek - Brown or Mohr Coulomb criteria) can be determined for any orientation of the anisotropy plane, while the least strength of the anisotropic rock mass occurs when the orientation of the anisotropy plane is such that failure takes place along the anisotropy plane, usually at an angle between 30 to $45^{\circ}$.

In the present paper a comparison between these two approaches is performed using a strongly anisotropic rock mass from an open pit mine in the Pilbara region of Western Australia.

\section{Anisotropic rock mass rating (ARMR)}

The behavior of anisotropic rock masses is generally dictated by two key aspects - inherent strength anisotropy and structure anisotropy [8].

Inherent strength anisotropy within the intact rock due to the variation of uniaxial compressive strength (UCS) with respect to the direction of loading relative to the plane of anisotropy (measured in degrees, $\beta$ ). The anisotropy of intact rock can be characterized by the strength anisotropy index $\left(R_{c}\right)$ which was defined by Saroglou and Tsiambaos [7] as: 
$R_{c}=\frac{k_{\beta=90^{\circ}}}{k_{\beta \min }}=\frac{1}{k_{\beta=30^{\circ}}}=\frac{\sigma_{c, \beta=90^{\circ}}}{\sigma_{c, \beta \min }}$,

where $k_{\beta=90^{\circ}}$ is the value of the parameter $k_{\beta}$ when the loading direction is perpendicular to the anisotropy plane, equal to unity. Typically, $k_{\beta=30^{\circ}}$ is the value at the orientation of minimal strength $\left(k_{\beta \min }\right)$, although this can range from $\beta=30-45^{\circ}$.

Structure anisotropy originates from the intensity of anisotropic structure (e.g. foliation, bedding etc.) and the quality or condition of the anisotropy surfaces.

Saroglou et al. [6] developed the anisotropic rock mass rating (ARMR) based on the rock mass rating (RMR) system by Bieniawski [9], which is the summation of the following classification parameter ratings (Table 1):

A. Strength anisotropy index, $R_{c}$ based on Eq. (1).

B. Uniaxial compressive strength of intact rock, $\sigma_{c}$, in which the loading direction is applied perpendicular to the anisotropy planes. When laboratory tests are not available, field estimates and point load tests are possible.

C. Degree of structure anisotropy (spacing of anisotropy planes). Scale effects have an influence on the degree of structure anisotropy; so an appropriate scale must be used. For example, when planning a tunnel excavation of say 1 to $10 \mathrm{~m}$ diameter, an appropriate scale for characterizing the degree of structure anisotropy would be in the order of 5 to $10 \mathrm{~m}$.

D. Corrected rock quality designation ( $\mathrm{RQD}_{\mathrm{c}}$ ) whereby the principal anisotropy plane is omitted from calculations. This reduces the direction-dependence of RQD that can arise from poor sampling with 'higher values' when drilled parallel to anisotropy planes or 'lower values' when drilled perpendicular to anisotropy [10].

E. Condition of anisotropy surfaces based on $\mathrm{RMR}_{89}$ [9] considering discontinuity length, aperture, roughness, infilling and weathering.

Table 1 Anisotropic rock mass rating (ARMR); classification parameters

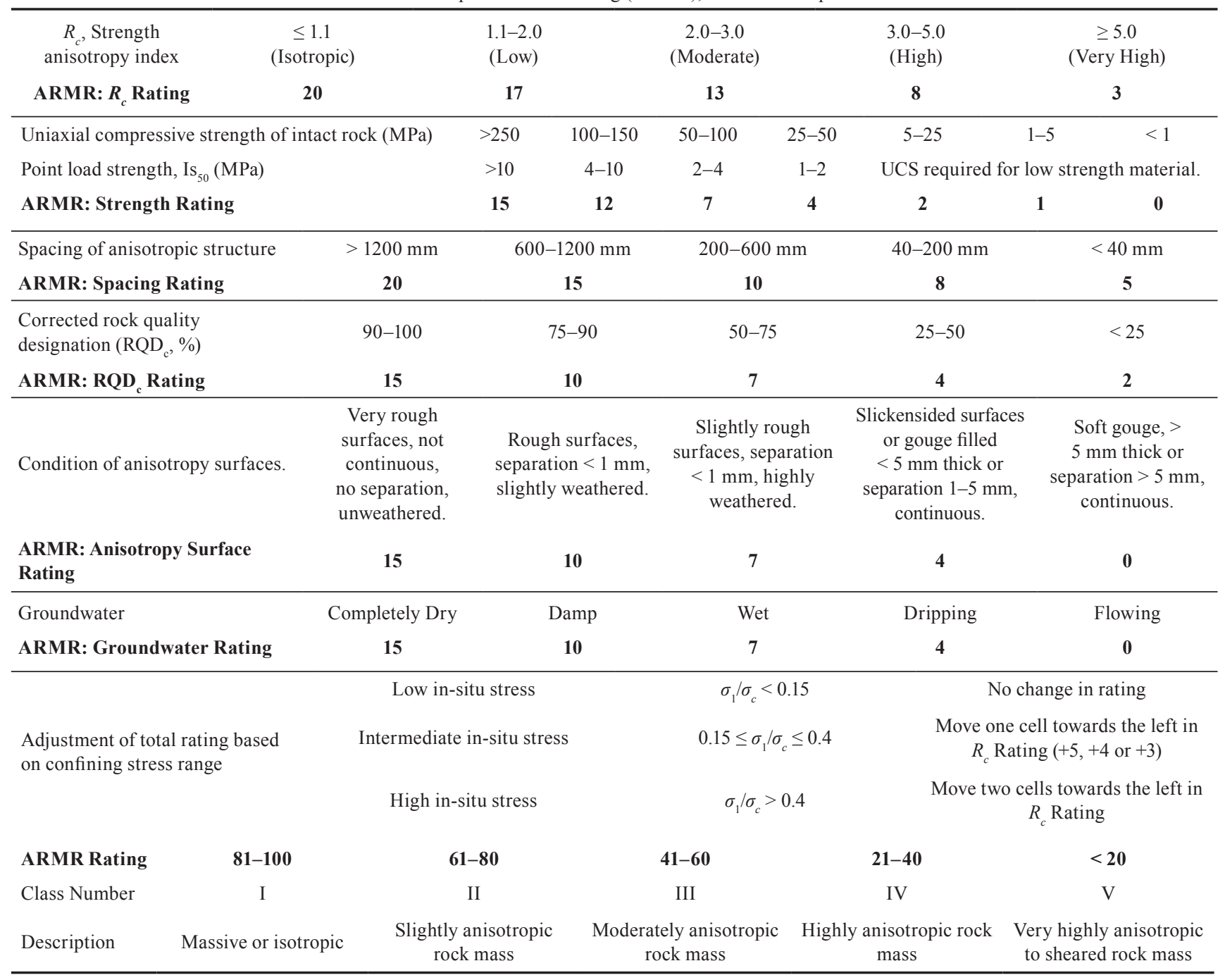


F. Groundwater conditions since they influence the mechanical response of rock masses.

G. Confining stress range adjustments are made to the final rating to effectively reduce the influence of anisotropy as in-situ stresses increase.

\section{The modified Hoek-Brown failure criterion}

The Hoek-Brown failure criterion is widely used to estimate the strength of isotropic rock masses [3]. The Modified Hoek-Brown failure criterion for anisotropic rock [6] is used to estimate the strength of anisotropic rock at different orientations. The modified criterion has been linked with ARMR to derive a criterion for anisotropic rock masses that takes into account:

1. The orientation of anisotropy within the rock mass relative to the direction of loading through parameter $k_{\beta}$.

2. The degree of structure anisotropy (spacing of anisotropy planes) through the ARMR classification.

The total ARMR value is effectively used as a replacement of the GSI (geological strength index) $[11,12]$ in the Modified Hoek-Brown failure criterion as described in Eq. (2)-(5).

$\sigma_{1}=\sigma_{3}+\sigma_{c i, \beta}\left(k_{\beta}\left(m_{b, a n}\left(\frac{\sigma_{3}}{\sigma_{c i, \beta}}\right)+s_{a n}\right)\right)^{a}$,

where $\sigma_{1}=$ major principal stress at failure.

$\sigma_{3}=$ minor principal stress at failure.

$\sigma_{c i, \beta}=$ uniaxial compressive strength of intact rock at orientation of anisotropy, $\beta$.

$\sigma_{b, a n}=$ reduced value of $m_{i}$ parameter for anisotropic rock mass, shown in Eq. (3).

$s_{a n}$ and $a$ are constants related to the orientation of anisotropy shown in Eq. (3) and Eq. (4), respectively.

$m_{i}=$ dimensionless Hoek-Brown material constant for intact rock.

$D=$ disturbance factor [3].

$m_{b, a n}=m_{i} \exp \left(\frac{A R M R-100}{28-14 D}\right)$

$S_{a n}=\exp \left(\frac{A R M R-100}{9-3 D}\right)$

$a=0.5+\frac{1}{6}\left(e^{-A R M R / 15}-e^{-20 / 3}\right)$

The strength of the anisotropic rock mass, $\sigma_{c m, a n}$ is given by Eq. (6) $\sigma_{c m, a n}=\sigma_{c i, \beta}\left(\frac{\left(m_{b, a n}+4 s_{a n}-a\left(m_{b, a n}-8 s_{a n}\right)\right)\left(m_{b, a n} / 4+s_{a n}\right)^{a-1}}{2(1+a)(2+a)}\right)$

\section{Case study: Weathered shale in an iron ore mine}

Australia is host to many anisotropic rocks and rock masses. Strong banded iron interbedded with weak shales in the Pilbara region of Western Australia are a typical example of anisotropic rock masses found in the iron ore mining industry [1]. Fig. 1 displays photographs of smooth, undulating bedding (anisotropy) in a moderately to highly weathered Mount McRae Shale from an iron ore mine in Western Australia.

The strength anisotropy index, $R$, for weathered shales is approximately 4 as illustrated in Fig. 2. The lowest average strength, approximately $6 \mathrm{MPa}$ is achieved when $\beta$ is between $35^{\circ}$ and $45^{\circ}$.

Typically, anisotropy plane spacing is in the order of $150 \mathrm{~mm}$, although with cross-jointing, the average



Fig. 1 A: Undulating smooth bedding planes in moderately to highly weathered Mount McRae Shale with limited cross-jointing; B: Example of weathered (white-pink) and fresh (black) Mount McRae Shale in an open cast mine 
uncorrected RQD is about $30 \%$. Once correct to remove anisotropy from the RQD, it ranges from 90-100\%.

Anisotropy plane surface conditions are smooth and undulating, highly weathered and with $<1 \mathrm{~mm}$ of silty to clayey infilling. Barton-Bandis shear strength parameters $[4,5]$ have been estimated for the shale bedding planes with a mean $\mathrm{JRC}_{\mathrm{n}}$ of $1.5, \mathrm{JCS}_{\mathrm{n}}$ of $13 \mathrm{MPa}$ and residual friction angle $27^{\circ}$ from drill core logging direct shear tests.

Weathered shale usually occurs above the groundwater table and exposures are dry. Slope heights, including overburden above the shale range between 100 and 300 meters. Table 2 presents a summary of ARMR estimation for weathered Mount McRae Shale for this case study.

No direct relationship between ARMR and GSI has been established. For comparative purposes in this case
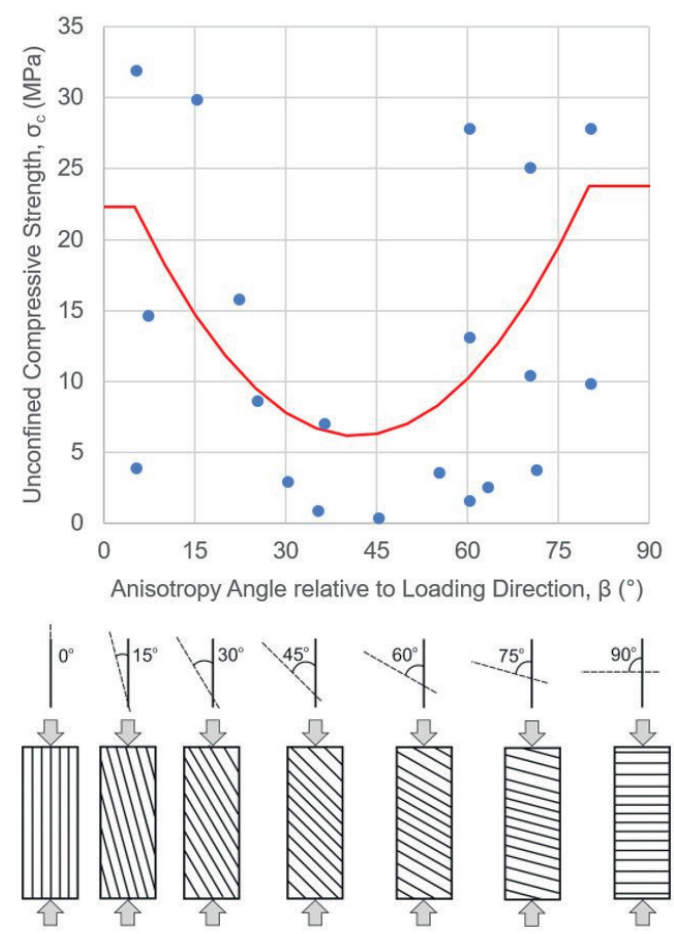

Fig. 2 Inherent anisotropy from unconfined compressive strength (UCS) testing in moderately to highly weathered shales from the Pilbara region of Western Australia

Table 2 ARMR for Weathered Mount McRae Shale Case Study

\begin{tabular}{lc}
\hline$R_{c}$ Rating & 17 \\
Strength Rating & 4 \\
Spacing Rating & 8 \\
RQDc Rating & 15 \\
Anisotropy Surface Rating & 7 \\
Groundwater Rating & 15 \\
Stress Adjustments & 0 \\
ARMR Rating & 66 \\
\hline
\end{tabular}

study, GSI typically ranged between 50 and 60 . The constant mi for the shale, based on laboratory testing and literature, is considered equal to 7 .

\section{Shear strength}

The shear strength of the rock mass was estimated using both the original Hoek-Brown criterion for rock mass and BartonBandis criterion for bedding planes as well as the Modified Hoek-Brown for the anisotropic rock mass at different orientations of loading relative to the bedding planes. Fig. 3 shows the non-linear shear strength envelopes of the rock mass, using Hoek-Brown criterion and of bedding using BartonBandis criterion, for normal stress up to $1.5 \mathrm{MPa}$. The shear strength envelopes of the anisotropic rock mass, derived using the Modified Hoek-Brown criterion and ARMR, have been plotted for the same stress range. The envelopes refer to the following orientations of anisotropy planes:

a) $\beta=90^{\circ}$ (maximum strength envelope),

b) $\beta=40^{\circ}$ (minimum strength envelope when failure occurs almost along bedding planes), and

c) $\beta=7.5$ and $75^{\circ}$.

The Barton-Bandis strength envelope of the bedding planes is slightly lower than the minimum strength envelope of the rock mass, derived using the Modified Hoek-Brown criterion. This is anticipated, as the second one predicts the strength of the rock mass when failure will occur primarily

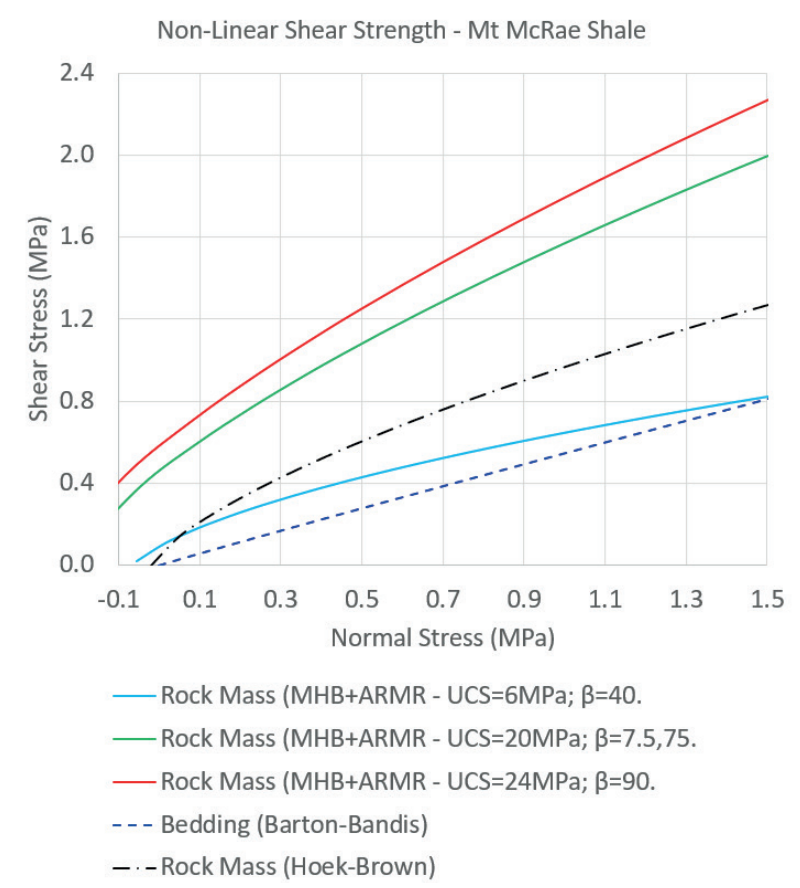

Fig. 3 Comparison of failure envelopes of rock mass using Hoek-Brown and Modified Hoek-Brown criteria with ARMR, and bedding shear strength from Barton-Bandis 
along the bedding planes and also through failure of rock mass bridges when the orientation of bedding is $\beta=40^{\circ}$.

Fig. 4 illustrates a directional shear strength model with bedding dipping at $+40^{\circ}$ calculated both with the conventional Hoek-Brown and Barton-Bandis approaches and the ARMR and modified Hoek-Brown approach. The anisotropic linear model transition parameters were $\mathrm{A}=10^{\circ}$ and $\mathrm{B}=30^{\circ}$.

Considering the above, it may be concluded that rock mass shear strength is underestimated in directions sub-perpendicular to the bedding by the conventional Hoek-Brown shear strength model. This is true for the range of normal stresses considered (0.3 MPa, 0.5 MPa, and 0.7 MPa).

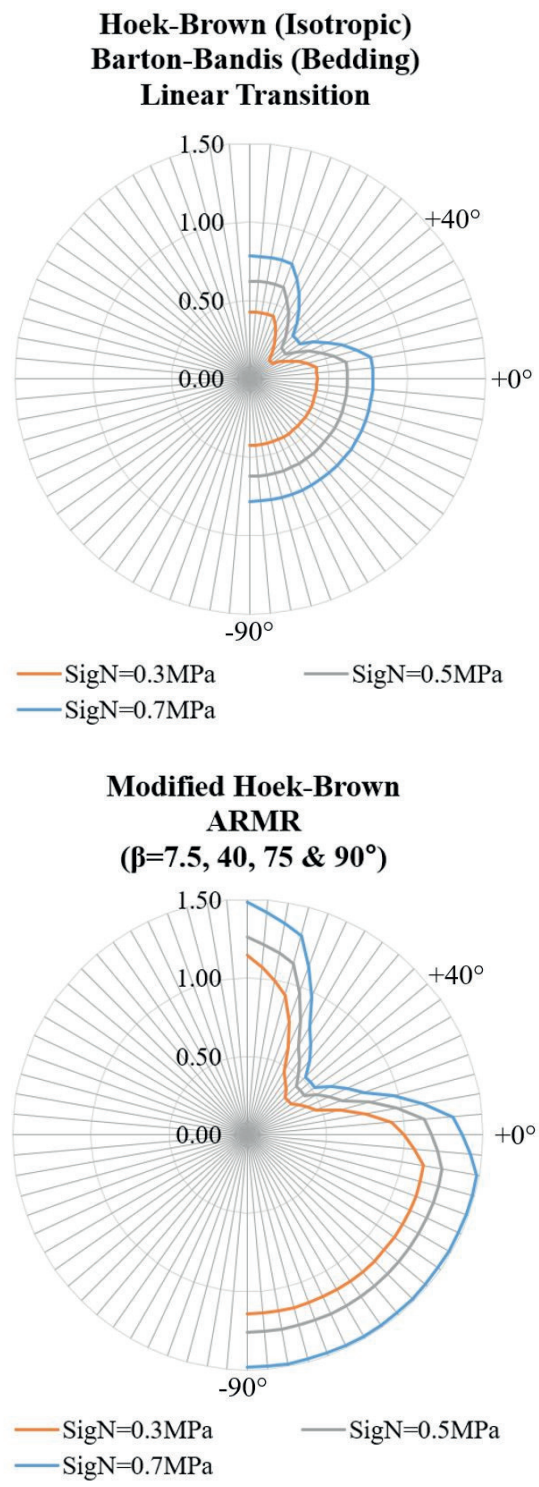

Fig. 4 Anisotropic linear directional shear strength model comparison; Top: Modified Hoek-Brown and ARMR approach; Bottom: Conventional Hoek-Brown (isotropic) approach using Barton-Bandis for bedding shear strength (Transition Parameters: $\mathrm{A}=10^{\circ} ; \mathrm{B}=30^{\circ}$ )

\section{Stability analysis}

Limit equilibrium analysis using both the conventional directional shear strength model and the Modified HoekBrown failure criterion have been undertaken for the examined case study.

As shown in Fig. 5, a $120 \mathrm{~m}$ high slope comprising Mt McRae Shale (yellow color) with favorably oriented bedding, overlain by far heavier, Dales Gorge Member (banded iron formation - green color) was assessed.

Directional shear strength models were incorporated in order to allow the application of different shear strengths to different slip surface orientations to simulate anisotropic behavior.

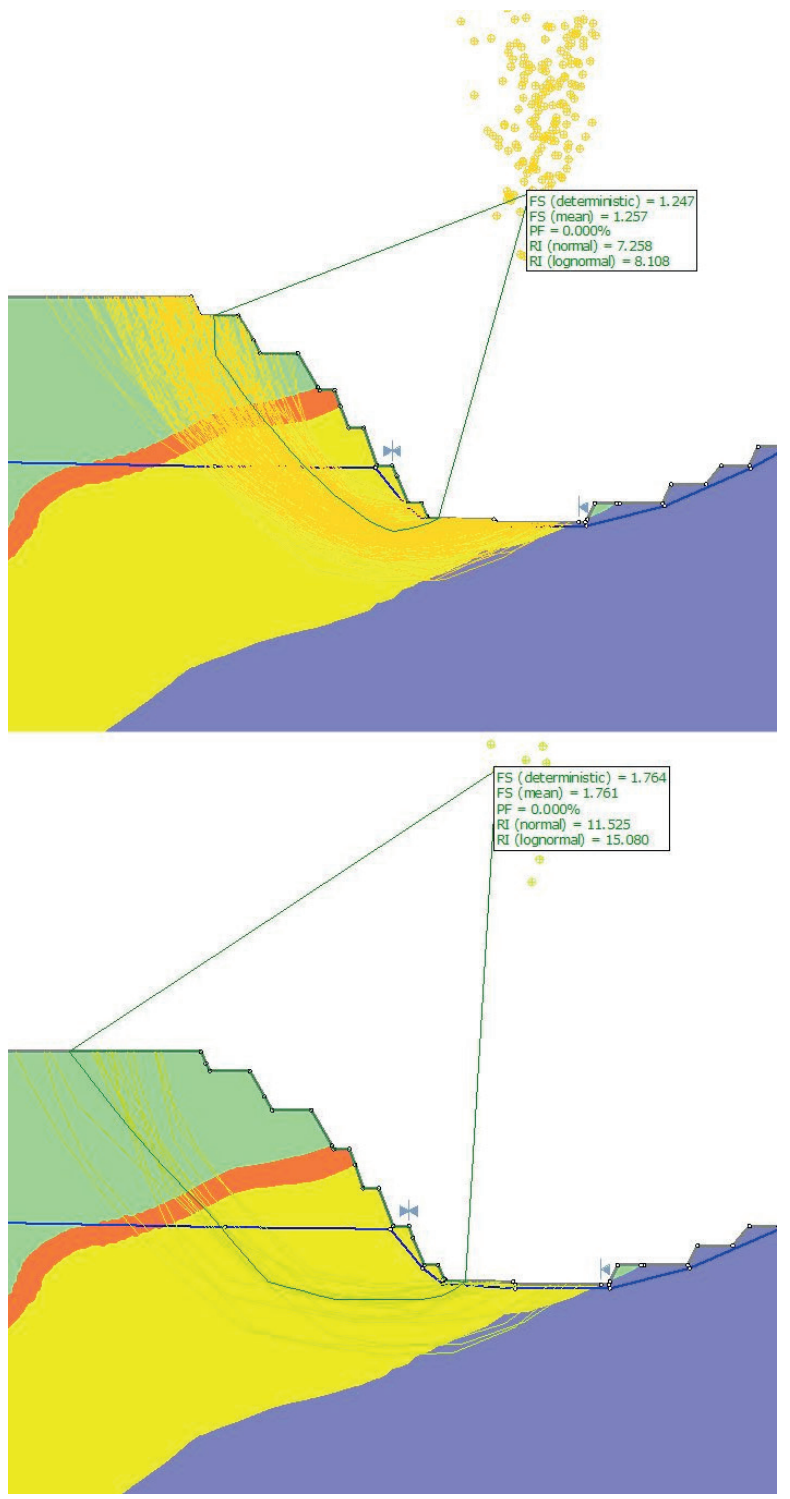

Fig. 5 Stability analysis; Top: Results from conventional Hoek-Brown (isotropic) approach using Barton-Bandis for bedding shear strength relatively shallow failure mechanism with FoS $>1.2$; Bottom: Results from modified Hoek-Brown and ARMR approach - deeper seated failure mechanism with $\mathrm{FoS}>1.7$ 
The modeling results were different with the conventional Hoek-Brown (isotropic) approach using BartonBandis for bedding shear strength attaining a much lower factor of safety (FoS) of approximately 1.2 compared to the Modified Hoek-Brown and ARMR approach, which attained a FoS $>1.7$.

The different factors of safety were accompanied by different failure mechanisms as shown in Fig. 5. Of course, it should be mentioned that the examined slope is generally stable due to the favorable orientation of the bedding, thus the FoS in both cases are relatively high.

\section{Conclusions}

Based on the results of the present study, it was evident that the strength of anisotropic rock masses for different orientations of the anisotropy plane can be effectively determined by using the anisotropic rock mass rating system ARMR in conjunction with the Modified HoekBrown failure criterion.

The maximum strength of the anisotropic rock mass determined with the modified criterion was higher than that determined by the isotropic Hoek-Brown criterion while the minimum strength of the anisotropic rock mass,

\section{References}

[1] Bar, N., Johnson, T. M., Weekes, G. "Using directional shear stress models to predict slope stability in highly anisotropic rock masses", In: Ulusay, R., Aydan, O., Gerçek, H., Hindistan, M. A., Tuncay, E. (eds.) Rock Mechanics and Rock Engineering: From the Past to the Future: Proceedings of the 2016 ISRM International Symposium, EUROCK 2016, Cappadocia, Turkey, 29-31 August 2016, CRC Press/Belkema, Leiden, Netherlands, 2016, pp. 595-600. https://doi.org/10.1201/9781315388502-103

[2] Bar, N., Weekes, G. "Directional shear strength models in 2D and 3D limit equilibrium analyses to assess the stability of anisotropic rock slopes in the Pilbara Region of Western Australia", Australian Geomechanics Journal, 52(4), pp. 91-104, 2017.

[3] Hoek, E., Carranza-Torres, C., Corkum, B. "The Hoek-Brown failure criterion - 2002 edition", In: Proceedings of the 5th Northern American Rock Mechanics Symposium and 17th Tunneling Association of Canada Conference (NARMS-TAC), Toronto, Canada, 2002, pp. 267-271.

[4] Barton, N., Bandis, S. "Some effects of scale on the shear strength of joints", International Journal of Rock Mechanics and Mining Science \& Geomechanics Abstracts, 17(1), pp. 69-73, 1980. https://doi.org/10.1016/0148-9062(80)90009-1

[5] Barton, N., Bandis, S. "Review of predictive capabilities of JRCJCS model in engineering practice", In: Rock Joints: Proceedings of the International Symposium on Rock Joints, Loen, Norway, 1990, pp. 603-610.

[6] Saroglou, C., Qi, S., Guo, S., Wu, F. "ARMR, a new classification system for the rating of anisotropic rock masses", Bulletin of EngineeringGeologyandtheEnvironment, 78(5),2018,pp.3611-3626. https://doi.org/10.1007/s10064-018-1369-4 applicable when failure occurs primarily along the bedding planes, is slightly higher than that derived by the Barton-Bandis criterion. Overall, it is expected that the conventional directional shear strength modeling methods are likely less realistic compared to the proposed approach, using the anisotropic rock mass rating system, ARMR, and the Modified Hoek-Brown failure criterion.

A distinct advantage of ARMR and the Modified HoekBrown criterion is that both the 'transition' from intact rock or rock mass shear strength to anisotropy plane shear strength and directionally-dependent shear strengths can be logically derived.

The factor of safety obtained from subsequent stability analyses is expected to be lower when using the conventional directional shear strength modeling method. However, it should be mentioned, that these findings should be further verified with more case studies.

Notwithstanding the present findings, it remains evident that for discontinuity-controlled sliding, the use of the Modified Hoek-Brown and ARMR approach is not applicable, as it considers the rock mass in a given orientation rather than a specific, discrete feature. In such cases, the Barton-Bandis failure criterion should be used.

[7] Saroglou, H., Tsiambaos, G. "A modified Hoek-Brown failure criterion for anisotropic intact rock", International Journal of Rock Mechanics and Mining Sciences, 45(2), pp. 223-234, 2008. https://doi.org/10.1016/j.ijrmms.2007.05.004

[8] Saroglou, H. "Engineering Behavior of anisotropic and heterogeneous layered rocks", In: IAEG Conference: Global View of Engineering Geology and the Environment, Beijing, China, 2013, pp. 721-731.

https://doi.org/10.1201/b15794-116

[9] Bieniawski, Z. T. "Engineering rock mass classifications", John Wiley \& Sons Inc., Toronto, Canada, 1989.

[10] Barton, N., Quadros, E. "Anisotropy is Everywhere, to See, to Measure, and to Model", Rock Mechanics and Rock Engineering, 48(4), pp. 1323-1339, 2015.

https://doi.org/10.1007/s00603-014-0632-7

[11] Somodi, G., Krupa, A., Kovács, L., Vásárhelyi, B. "Comparison of different calculation methods of Geological Strength Index (GSI) in a specific underground construction site", Engineering Geology, 243, pp. 50-58, 2018.

https://doi.org/10.1016/j.enggeo.2018.06.010

[12] Vásárhelyi, B., Somodi, G., Krupa, A., Kovács, L. "Determining the Geological Strength Index (GSI) using different methods", In: Ulusay, R., Aydan, O., Gerçek, H., Hindistan, M. A., Tuncay, E. (eds.) Rock Mechanics and Rock Engineering: From the Past to the Future: Proceedings of the 2016 ISRM International Symposium, EUROCK 2016, Cappadocia, Turkey, 29-31 August 2016, CRC Press/Belkema, Leiden, Netherlands, 2016, pp. 1049-1054. https://doi.org/10.1201/9781315388502-183 